\title{
The use of anthropometrical variables for detection of homeostatic measurement assessment-insulin resistance (HOMA-IR) in female participants of a physical exercise program
}

\author{
Ruiz-Montero $\mathrm{PJ}^{1}$, González-Fernández $\mathrm{FT}^{2}$, Mikalacki $\mathrm{M}^{3}$, Martín-Moya ${ }^{4}$ \\ Department of Physical Education and Sport, Faculty of Education and Sport Sciences, Campus of Melilla, \\ University of Granada, Melilla, Spain. ftgonzalez@comillas.edu
}

\begin{abstract}
BACKGROUND: The Homeostatic Measurement Assessment-Insulin Resistance (HOMA-IR) is a recognized and validated method which uses the levels of fasting glucose in blood and insulin of patients to evaluate the insulin resistance.

AIMS: The purpose of the present study was to assess the cut-off values for anthropological variables to identify the (HOMA-IR) index in female participants of a physical exercise program. In addition, the association and prediction of insulin resistance by anthropological variables was studied.

METHODS: A total of 143 participants (45.64 \pm 13.17 years) volunteered for this study. Clinical data were collected by means of a self-reported questionnaire. Body weight and BMI were assessed by bioelectrical impedance analysis and skinfold thickness was taken using a caliper. Girths were assessed with a flexible metallic tape measures and finally, the HOMA-IR was calculated by the formula as follows: fasting plasma insulin $((\mu \mathrm{U} / \mathrm{ml}) \times$ fasting plasma glucose $(\mathrm{mmol} / \mathrm{L})$.

RESULTS: The outcomes of the study indicated that the AUC of anthropometrical variables for identifying HOMA-IR are reflected primarily in weight, waist-to-hip ratio, waist-to-thigh ratio, subscapular skinfold thickness, abdominal skinfold thickness, hip circumference, chest circumference, upper arm muscular girths (tensed and relaxed) (all, $p \leq 0.001)$, triceps skinfold thickness $(p<0.01)$, and waist circumference $(p<$ $0.05)$. In that respect, the optimal cut-off values, sensitivity, specificity and possibility of predicting variables for detecting HOMA-IR showed that hip circumference $>100 \mathrm{~cm}$ (specificity: $98.4 \%$ ), chest circumference $>109 \mathrm{~cm}$ (specificity: 99.2 waist circumference > $116 \mathrm{~cm}$ (specificity: $99.2 \%$ ) and abdomen skinfold $<8.8$ (specificity: $97.6 \%$ ), predict the HOMA-IR in $35.29 \%, 29.41 \%, 23.53 \%$ and $23.53 \%$, respectively.

CONCLUSION: The present empirical study demonstrates that hip, chest and waist circumference on the one hand, and abdomen skinfold on the other hand are markers that are relevant to the identification of HOMA-IR index in females (Tab. 3, Ref. 33). Text in PDF www.elis.sk

KEY WORDS: insulin resistance, anthropometry, cut-off value, women, HOMA-IR.
\end{abstract}

\section{Introduction}

Changes in body composition are considered one of the major causes of chronic diseases of adult and ageing people (1-2) and have become a primary concern (3). Body composition is an important marker of health, predictor of comorbidities (4), and component of good health and disease prevention associated with physical fitness and exercise (5). Skeletal muscle mass (SMM) and fat mass

${ }^{1}$ Department of Physical Education and Sport, Faculty of Education and Sport Sciences, Campus of Melilla, University of Granada, Melilla, Spain, ${ }^{2}$ Department of Physical Activity and Sports Sciences, Pontifical University of Comillas. CESAG, Mallorca, Spain, ${ }^{3}$ Faculty of Sport and Physical Education, University of Novi Sad, Novi Sad, Serbia, and ${ }^{4}$ Department of Physical Education and Sport, Faculty of Education and Sport Sciences, Campus of Melilla, University of Granada, Melilla, Spain

Address for correspondence: F.T. González-Fernández, Department of Physical Activity and Sports Sciences, Pontifical University of Comillas, CESAG, Mallorca, Spain.

Phone: \pm 0034686966235
(FM) are body composition states that change continuously (6). In fact, these changes can be seen in variations in body composition after middle age (7) through the increase in FM, reduction in SMM (8-9) and decrease in fat-free mass (FFM) (10). Furthermore, maximum levels of FFM are present at 20 years of age. After that, the latter levels begin to decrease, and by 70 years of age, the decrease reaches $40 \%$, primarily in form of skeletal muscle loss (11). This is the major drawback of body mass index (BMI) (10). Nevertheless, BMI is a suitable method when it is necessary to classify the medical risk by weight status (12) such as obesity (13).

Obesity is considered a widespread health problem in the developing countries, where it is accompanied by chronic morbidities, functional impairment and premature mortality (14). Moreover, obesity is associated with the prevalence of diseases such as diabetes, hypertension, arthritis, cardiovascular risk, T2 diabetes $(15)$ or metabolic syndrome $(15,16)$. Majority of those diseases show a considerable resistance to insulin (17) and association with mortality, increased secretion and decreased sensibility to this hepatic hormone (18). 
The Homeostatic Measurement Assessment-Insulin Resistance (HOMA-IR) is a recognized and validated method which uses the level of fasting glucose in blood and insulin of patients to evaluate insulin resistance. It is a common method standardized in epidemiological researches since 1985 (19). However, previous studies have not yet obtained conclusions about the use of cut-off points in the diagnosis of insulin resistance (20). On the other hand, several studies have been carried out with anthropometrical variables such as BMI, circumferences, subcutaneous skinfold thickness or muscular girths to predict the level of insulin resistance $(21,22)$.

The present study aimed to assess the cut-off values for anthropological variables to identify HOMA-IR index in female participants of a physical exercise program. In addition, we studied the association and prediction of insulin resistance by anthropological variables.

\section{Material and methods}

\section{Participants}

The participants of present study were recruited from a fitness programs via letter or telephone. Female participants were attendants of a Pilates and aerobic-physical exercise interventional program conducted by the Faculty of Sport of Novi Sad (Serbia) (23).

A total of 143 female participants and 8 male participants volunteered for this study. It was decided to exclude the men due to their low attendance. The women's age ranged between 40 and 80 years. The participants were informed of the purpose of this study and voluntarily agreed to participate by signing the informed consent. The inclusion criterions of participants were as follows: i) not to have acute or terminal illness, ii) not to have functional mobility limited, iii) to be able to communicate (Tab. 1).

Measurements obtained were age, BMI, body weight, waist-tohip ratio, waist-to-thigh ratio, waist-to-height ratio, subcutaneous skinfold thickness (subscapularis, triceps, abdomen, front thigh and medial calf), waist and hip circumference, muscular girths (upper arm relaxed, upper arm flexed and tensed), chest circumference and HOMA-IR.

Written informed consent was accepted by all participants after receiving detailed information about the main objective and study procedures of the current project which complied with the guidelines of the Declaration of Helsinki. The present study was reviewed and approved by the Ethics Committee of the University of Novi Sad.

\section{Measurements}

Clinical data were collected by means of a self-reported questionnaire.

Body weight and BMI were gained by using bioelectrical impedance analysis with a Tanita SC 330s with participants wearing light indoor clothing and no shoes. Measurements were performed following the standardized techniques adopted by the International Society for the Advancement of Kinanthropometry (ISAK) (24). The technical error of measurement was lower than $5 \%$ for skinfold thickness and lower than $1 \%$ for the rest of other measurements. Skinfold thickness was taken using a caliper with a precision of $0.2 \mathrm{~mm}$ (Holtain Ltd, Crymych, UK). Girth data were obtained with a flexible metallic tape measure with a precision of $0.1 \mathrm{~mm}$. The HOMA-IR was calculated by a formula as follows: fasting plasma insulin $((\mu \mathrm{U} / \mathrm{ml}) \times$ fasting plasma glucose $(\mathrm{mmol} / \mathrm{L})(19)$. 


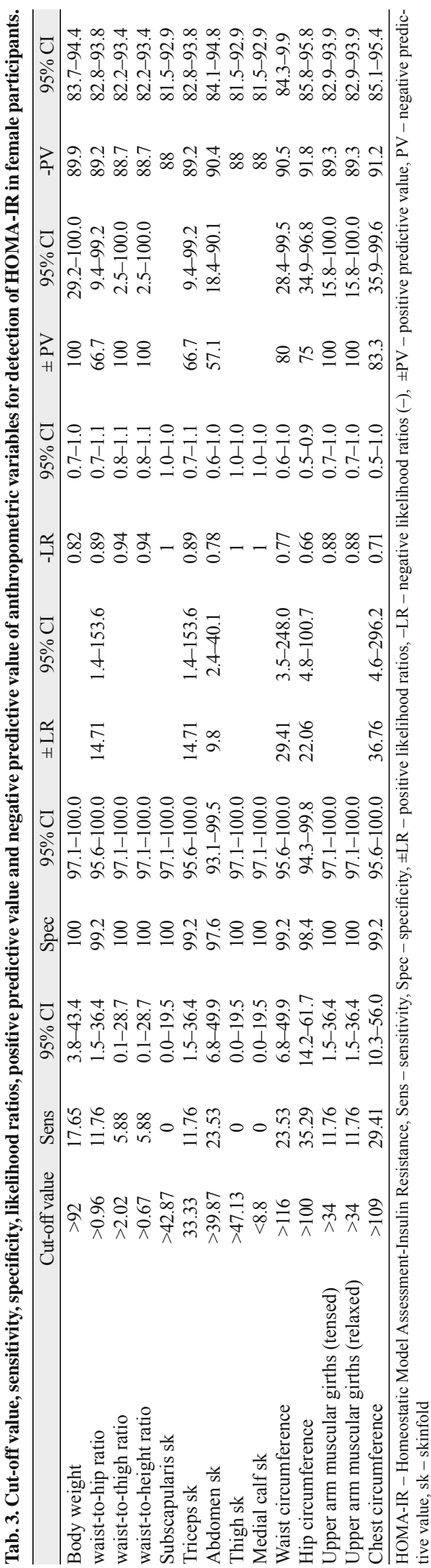

\section{Procedure}

The cross-sectional study was carried out with homogeneous samples of Serbian female participants who were attending a program of educational and physical exercise based on Pilates and aerobic exercise. The data were collected in two one-week sessions. Firstly, the anthropometric measurement was carried out in a covered room with temperature in range of $17-22^{\circ} \mathrm{C}$. On the second day, the assays were carried out using the Roche modular p800 analyser for glucose and Roche modular E170 for insulin. The laboratory assays were performed in the laboratory unit of the Department of Anatomy, Faculty of Medicine, University of Novi Sad (Serbia). The measurements were obtained by the same group of trained researchers and clinicians in order to reduce inter-examiner error.

The concepts of health education were given at the beginning of sessions of the interventional program in order to orientate participants towards a healthier posture and practice of food hygiene in their daily lives. The controlled diet was established according to the recommendations of the American College of Sport Medicine guidelines (25).

\section{Statistical analysis}

The normal distribution of data was studied using the Kolmogorov-Smirnov test. The descriptive analyses were carried out to check the clinical characteristics of the participants, namely mean data, standard deviation (SD), minimum and maximum value for female participants. The receiver operating characteristics (ROC) curve of anthropometrical variables for the detection of HOMA-IR was depicted for the total of subjects in the studied sample (26). The areas under the ROC curve (AUC) with maximum Youden index were calculated to evaluate the accuracy of the anthropometrical variables. ROC curve is understood as the probability that the modeled phenotype can discriminate subjects developing end points from those without end points $(0.5 \sim 1.0)$ (27). The sensitivity, specificity, positive and negative predictive value, and positive and negative likelihood ratios were calculated for anthropological variables at each cut-off value for detection of HOMA-IR.

All statistical analyses were performed using the Statistical Package for Social Sciences (SPSS, v.17.0 for WINDOWS, SPSS Inc., Chicago, IL, USA).

\section{Results}

The clinical characteristics of participants are presented in Table 1 as means $\pm \mathrm{SD}$, minimum and maximum values of female participants in the present study. The mean values of age, BMI and HOMA-IR are $45.6 \pm 13.2$ years, $25.2 \pm 4.1 \mathrm{Kg} / \mathrm{m}^{2}$ and $1.3 \pm$ 0.9 , respectively. According to anthropological variables, the mean value of body weight is $67.3 \pm 10.6 \mathrm{Kg}, 0.8 \pm 0.1$ for waist-to-hip ratio, $1.4 \pm 0.2$ for waist-to-thigh ratio, $0.5 \pm 0.7$ for waist-to-height ratio, $19.7 \pm 7.9 \mathrm{~mm}$ for subscapularis skinfold thickness, $21.4 \pm$ $5.7 \mathrm{~mm}$ for triceps skinfold thickness, $25.9 \pm 8.9 \mathrm{~mm}$ for abdominal skinfold thickness, $33.9 \pm 8.3 \mathrm{~mm}$ for thigh skinfold thickness and $21.7 \pm 7.6 \mathrm{~mm}$ for medial calf skinfold thickness. The mean circumference for waist, hip and chest are $102.4 \pm 7.9 \mathrm{~cm}, 80.1$ 
$727-731$

$\pm 11.1 \mathrm{~cm}$ and $92.6 \pm 8.3$, respectively. Finally, the mean muscle perimeters for upper arm muscular girths (tensed and relaxed) are $29.5 \pm 3.9 \mathrm{~cm}$ and $28.2 \pm 3.4$, respectively.

The AUC of anthropometrical variables for identifying HOMA-IR are shown in Table 2. Female participants of the present study reported significant values in body weight, waist-tohip ratio, waist-to-height ratio, waist-to-thigh ratio, subscapularis skinfold thickness, abdominal skinfold thickness, hip circumference, chest circumference, upper arm muscular girths (tensed and relaxed) (all, p < 0.001), triceps skinfold thickness ( $<<0.01)$ and waist circumference $(\mathrm{p}<0.05)$ (Tab. 2).

In that respect, the optimal cut-off values, sensitivity, specificity and possibility of predicting variables for detecting HOMA-IR in our group of female participants, as well as negative predictive value of anthropometric variables for detection of HOMA-IR are shown in Table 3. For instance, the abdominal skinfold thickness $>$ $39.87 \mathrm{~mm}$ (specificity: $97.6 \%$ ) and the waist circumference $>116$ cm (specificity: $99.2 \%$ ) predict the HOMA-IR in $23.53 \%$ when the hip circumference $>100 \mathrm{~cm}$ (specificity: $98.4 \%$ ) and chest circumference $>109 \mathrm{~cm}$ (specificity: $99.2 \%$ ) predict the HOMAIR in $35.29 \%$ and $29.41 \%$, respectively (Tab. 3).

\section{Discussion}

The main objective of the present research was to assess the cut-of values for anthropological variables to identify HOMA-IR index in female participants of a physical exercise program. In addition, this study aimed to predict insulin resistance by means of anthropological variables. As it is well known, the scientific community considers HOMA-IR as a valid method of evaluating insulin resistance (28). Many investigators have taken this into consideration, which resulted in a rapid growth of the interest in this topic. However, to the best of our knowledge, there are not many specific studies investigating the HOMA-IR, different anthropological variables in a large group of women that perform long-term exercise (Pilates and aerobic exercise).

The outcome of the present study indicates that the AUC of anthropometrical variables for identifying HOMA-IR are shown significantly in weight, waist-to-hip ratio, waist-to-thigh ratio, subscapular skinfold thickness, abdominal skinfold thickness, hip circumference, chest circumference, upper arm muscular girths (tensed and relaxed), triceps skinfold thickness, and waist circumference. We can conclude that our results for AUC of anthropometrical variables were similar to the results of other studies. In this sense, Ying et al's study (29) reported that waist circumference correlated significantly with HOMA-IR in young and middle-aged woman. Therefore, this confirmed that BMI and waist circumference (correlated coefficient) were better predictors of cardiovascular diseases and diabetes mellitus. In fact, it is also recognized that among other cases, the risk of insulin resistance increases with obesity, age or physical inactivity, (30). In this sense, previous research has shown that BMI (bicipital fold and arm circumference) are the best predictors or insulin resistance in overweight adult population (31). Therefore, our results contribute to literature by pointing to other variables that can be employed in identification of HOMA-IR index in female participants of a physical exercise program (32).

High values of hip circumference, chest circumference, waist circumference and abdomen skinfold predict the HOMA-IR in $35.29 \%, 29.41 \%, 23.53 \%$ and $23.53 \%$ respectively. These results are in accord with Geloneze et al2006, who investigated the cut-off values for HOMA-IR in non-diabetic participants (18 to 78 years old). In fact, with an updated database and a larger sample, the found value of 2.7 was equivalent, thus reinforcing the concept that it is a useful reference for adult population. In this sense, other studies showed similar cut-off values for HOMA-IR indexes in different populations (33). It is our consideration that since the interactions of insulin resistance reflect in HOMA-IR and obesity in general population (17), using HOMA-IR can be a useful and reliable tool for early identification of insulin resistance as well as predicting and detecting different risks associated with it.

\section{Conclusions}

In conclusion, the present empirical study demonstrates that hip, chest and waist circumference on the one hand and abdomen skinfold on the other hand are relevant markers for identifying the HOMA-IR index in females. Therefore, a reduction in abdominal obesity primarily by weight reduction and physical exercise may help in preventing type 2 diabetes and cardiovascular disease. It also contributes to the extensive research on the use of anthropometrical variables for detecting HOMA-IR and opens interesting avenues for future research.

\section{References}

1. Medhi GK, Mahanta J. Population ageing in India: Health promotion through life course approach. Curr Sci 2007; 93: 1046.

2. Kyle UG, Morabia A, Schutz Y, Pichard C. Sedentarism affects body fat mass index and fat-free mass index in adults aged 18 to 98 years. Nutrition 2004; 20: 255-260. https://doi.org/10.1016/j.nut.2003.11.019.

3. Bae CY, Kang YG, Suh YS, Han JH, Kim SS, Shim KW. A model for estimating body shape biological age based on clinical parameters associated with body composition. Clin Interv Aging 2013; 8: 11-18. https:// doi.org/10.2147/CIA.S38220 .

4. Aparicio V, Carbonell-Baeza A, Delgado-Fernández M. Health benefits of physical activity in older people. Rev Int Med Cienc Act Fís Deporte 2010; 10: 556-576.

5. Castillo-Garzon MJ, Ruiz JR, Ortega FB, Gutierrez A. Anti-aging therapy through fitness enhancement. Clin Interv Aging. 2006; 1: 213-220. https://doi.org/10.2147/ciia.2006.1.3.213.

6. He Q, Heo M, Heshka S, Wang J, Pierson RN, Albu J et al. Total body potassium differs by sex and race across the adult age span. Am J Clin Nutr 2003; 78: 72-77. https://doi.org/10.1093/ajcn/78.1.72.

7. Gallagher D, Visser M, deMeersman RE, Sepulveda D, Baumgartner RN, Pierson RN et al. Appendicular skeletal muscle mass: Effects of age, gender, and ethnicity. J Appl Physiol 1997; 83: 229-239. https:// doi.org/10.1152/jappl.1997.83.1.229.

8. Peake J, Della Gatta P, Cameron-Smith D. Aging and its effects on inflammation in skeletal muscle at rest and following exercise-induced 
muscle injury. Am J Physiol-Regul Integr Comp Physiol 2010; 298: R1485R95. https://doi.org/10.1152/ajpregu.00467.2009.

9. Colado JC, Garcia-Masso X, Rogers ME, Tella V, Benavent J, Dantas EH. Effects of Aquatic and Dry Land Resistance Training Devices on Body Composition and Physical Capacity in Postmenopausal Women. J Hum Kinet 2012; 32: 185-195. https://doi.org/10.2478/v10078-012-0035-3.

10. Amarya S, Singh K, Sabharwal M. Health consequences of obesity in the elderly. J Clin Gerontol Geriatr 2014; 5: 63-67. https://doi. org/10.1016/j.jcgg.2014.01.004.

11. Baumgartner RN, Stauber PM, McHugh D, Koehler KM, Garry PJ. Cross-sectional age-differences in body-composition in person $60 \pm$ years of age. J Gerontol Ser A-Biol Sci Med Sci 1995; 50: 307-316. https:// doi.org/10.1093/gerona/50a.6.m307.

12. Kumanyika S, Brownson R, Satcher D. Handbook of obesity prevention: A resource for health professionals. New York, USA: Springer, 2007.

13. Dudeja V, Misra A, Pandey RM, Devina G, Kumar G, Vikram NK. BMI does not accurately predict overweight in Asian Indians in northern India. Br J Nutr 2001; 86: 105-12. https://doi.org/10.1079/bjn2001382.

14. Donini LM, Savina C, Coletti C, Paolini M, De Felice MR, Del Balzo V et al. Prevalence etiology and health consequences of obesity in the elderly. Agro Food Ind Hi-Tech 2006; 17 23-25.

15. Dror DM, van Putten-Rademaker O, Koren R. Cost of illness: Evidence from a study in five resource-poor locations in India. Indian J Med Res 2008; 127: 347-361. PMID: 18577789.

16. Yu ZJ, Lin X, Haas JD, Franco OH, Rennie KL, Li HX et al. Obesity related metabolic abnormalities: Distribution and geographic differences among middle-aged and older Chinese populations. Prev Med 2009; 48: 272-278. https://doi.org/10.1016/j.ypmed.2009.01.004.

17. Geloneze B, Vasques ACJ, Stabe CFC, Pareja JC, Rosado L, de Queiroz EC et al. HOMA1-IR and HOMA2-IR indexes in identifying insulin resistance and metabolic syndrome - Brazilian Metabolic Syndrome Study (BRAMS). Arq Bras Endocrinol Metabol 2009; 53: 281-287. https:// doi.org/10.1590/s0004-27302009000200020.

18. Haffner SM. Insulin resistance, inflammation, and the prediabetic state. Am J Cardiol 2003; 92: 18-26. https://doi.org/10.1016/s00029149(03)00612-x.

19. Matthews DR, Hosker JP, Rudenski AS, Naylor BA, Treacher DF, Turner RC. Homeostasis model assessment-Insulin resistance and beta-cell function from fasting plasma-glucose and insulin concentrations in man. Diabetologia 1985; 28: 412-419. https://doi.org/10.1007/ BF00280883.

20. Wongwananuruk T, Rattanachaiyanont $M$, Leerasiri P, Indhavivadhana S, Techatraisak K, Angsuwathana S et al. The Usefulness of Homeostatic Measurement Assessment-Insulin Resistance (HOMA-IR) for Detection of Glucose Intolerance in Thai Women of Reproductive Age with Polycystic Ovary Syndrome. Int J Endocrinol 2012: 6. https://doi. org/10.1155/2012/571035.

21. Gómez-García A, Nieto-Alcantar E, Gómez-Alonso C, FigueroaNuñez B, Álvarez-Aguilar C. Parámetros antropométricos como predictores de resistencia a la insulina en adultos con sobrepeso y obesidad. Aten Primaria 2010; 42: 364-371. https://doi.org/10.1016/j.aprim.2009.10.015.
22. Wahrenberg H, Hertel K, Leijonhufvud BM, Persson LG, Toft E, Arner P. Use of waist circumference to predict insulin resistance: retrospective study. Br Med J 2005; 330: 1363-1364. https://doi.org/10.1136/ bmj.38429.473310.AE.

23. Ruiz-Montero PJ, Castillo-Rodriguez A, Mikalacki M, Nebojsa C, Korovljev D. 24-weeks Pilates-aerobic and educative training to improve body fat mass in elderly Serbian women. Clin Interv Aging 2014; 9: 243-248. https://doi.org/10.2147/CIA.S52077.

24. Ross WD, Marfell-Jones MJ. Kinanthropometry. In: Mac Dougall JD, Wenger HA, Green HJ, eds. Physiological testing of elite athlete. London, UK: Human Kinetics; 1991. p. 223-308.

25. ACSM. Guidelines for Exercise Testing and Prescription. 8th ed. ed. Philadelphia, USA: Lippincott: Wilkins, and Williams; 2009.

26. Hanley JA, McNeil BJ. A method of comparing the areas under receiver operating characteristics curves derived from the same cases. Radiology 1983; 148: 839-843. https://doi.org/doi:10.1148/radiology.148.3.6878708.

27. Esteghamati A, Ashraf H, Khalilzadeh O, Zandieh A, Nakhjavani M, Rashidi A et al. Optimal cut-off of homeostasis model assessment of insulin resistance (HOMA-IR) for the diagnosis of metabolic syndrome: third national surveillance of risk factors of non-communicable diseases in Iran (SuRFNCD-2007). Nutr Metab 2010; 7: 26. https://doi. org/10.1186/1743-7075-7-26.

28. Geloneze B, Vasques AC, Stabe CF, Pareja JC, Rosado LE, Queiroz EC et al. HOMA1-IR and HOMA2-IR indexes in identifying insulin resistance and metabolic syndrome: Brazilian Metabolic Syndrome Study (BRAMS). Arq Bras Endocrinol Metabol 2009; 53: 281-287. https://doi. org/10.1590/s0004-27302009000200020.

29. Ying $\mathbf{X}$, Song ZY, Zhao CJ, Jiang Y. Body mass index, waist circumference, and cardiometabolic risk factors in young and middle-aged Chinese women. J Zhejiang Univ Sci B 2010; 11: 639-646. https://doi. org/10.1631/jzus.B1000105 .

30. Rader DJ. Effect of insulin resistance, dyslipidemia, and intra-abdominal adiposity on the development of cardiovascular disease and diabetes mellitus. Am J Med 2007;120: S12-S18. https://doi.org/10.1186/ s12933-018-0762-4.

31. Gómez-García A, Nieto-Alcantar E, Gómez-Alonso C, FigueroaNuñez B, Alvarez-Aguilar C. Anthropometric parameters as predictors of insulin resistance in overweight and obese adults. Aten Primaria 2010; 42: 364-371. https://doi.org/10.1016/j.aprim.2009.10.015.

32. Gayoso-Diz P, Otero-Gonzalez A, Rodriguez-Alvarez MX, Gude F, Cadarso-Suarez C, García F et al. Insulin resistance index (HOMA-IR) levels in a general adult population: curves percentile by gender and age. The EPIRCE study. Diabetes Res Clin Pract 2011; 94: 146-155. https:// doi.org/10.1016/j.diabres.2011.07.015.

33. Yeni-Komshian H, Carantoni M, Abbasi F, Reaven GM. Relationship between several surrogate estimates of insulin resistance and quantification of insulin-mediated glucose disposal in 490 healthy nondiabetic volunteers. Diabetes Care 2000; 23: 1711. https://doi.org/10.2337/diacare.23.2.171.

Received March 18, 2021. Accepted April 24, 2021. 